\title{
Inexplicable patients: the case of Charles Martell and Ward 4 at the Massachusetts General Hospital
}

I n January 1926, Dr. Eugene DuBois at Bellevue Hospital, New York City, admitted Charles Martell, a former captain in the United States Merchant Marines (Figure 1), to his metabolism clinic. Martell reported numerous ailments. He had joined the merchant marines in 1918. He was 22 years of age and stood over six feet tall. Seven years later, standing before DuBois, he measured seven inches shorter. His neck widened and abnormally barrel-chested, Martell reported a history of multiple fractures, disseminated pain, and his legs were observably deformed. ${ }^{1}$ Dubois was aware of research at the newly established Ward 4 at Massachusetts General Hospital that involved treatment of patients with lead-poisoning using the recently discovered parathyroid hormone. He referred Martell to Ward 4 with a provisionary diagnosis of hyperparathyroidism. ${ }^{2}$ According to documents in the hospital archives, Martell entered the annals of medical history as the first recorded patient in North America to be diagnosed with that rare condition. ${ }^{3}$

What is it like to be a "first patient?" Even as historians of medicine have embraced the historical study of patients, they have been reticent to evaluate patients without a diagnosis and for good reasons. ${ }^{4,5}$ In a sense, patients before discovery are beyond historical construction. They are subjects without sources. Such patients must exist in peculiar, liminal spaces. ${ }^{6}$ In the past they were often described euphemistically: inexplicables, incompletely understoods, incurables and even malingerers and simulators. A first patient stands in for all those who walked before them, observed but unknown, sometimes brushed off or maligned but, in any case, definitely not the first or a partners in discovery.

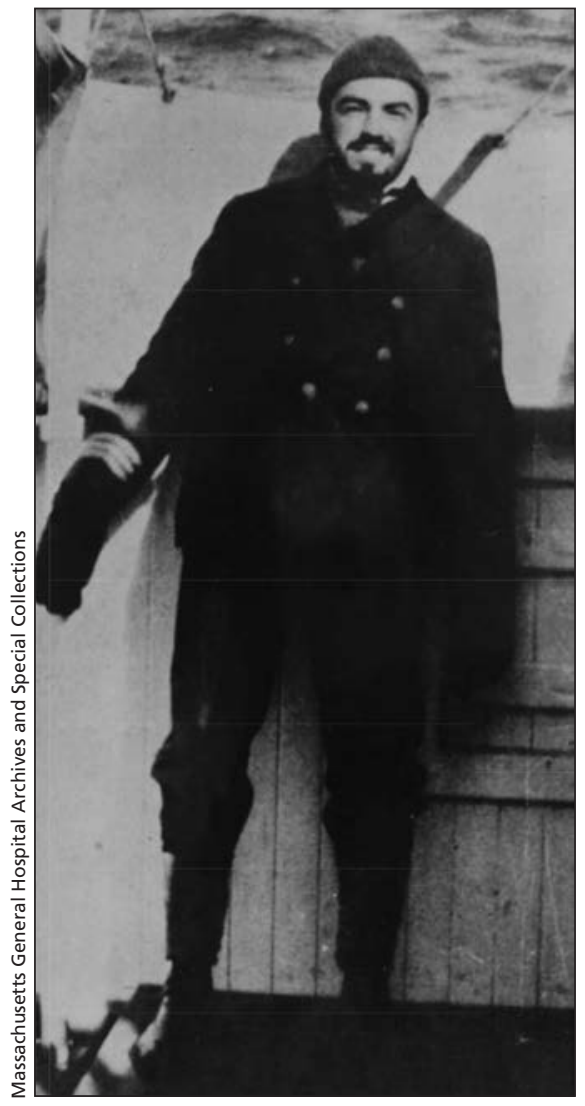

Figure 1: Charles Martell (published with permission from Archives and Special Collections of the Massachusetts General Hospital, Boston).

Certainly, Charles Martell, his family and his doctors existed in that liminal space for an extended period before he found his way to physicians with knowledge of metabolic disorders. The onset of his illness was 1919. By 1923, it had progressed to such a degree that he was forced to abandon his career. Nonetheless, it was not until 1926 that he would meet a physician who named his suffering. Seven years intervened between the onset of his illness and his entrance into DuBois' examination room. In those years, he had been stuck between his much evident experience and medical unfathomability.

When Martell arrived in 1926 at the Massachusetts General Hospital, Ward 4 had only begun receiving patients. Opened in November 1924, Ward 4 was founded by James Howard Means (1885-1967), the James Jackson Professor of Clinical Medicine at Harvard from 1923 to $1951 .^{7}$ Means had planned Ward 4 as a site of research into obscure medical conditions, a place where the proximity of beds to laboratories was meant to bring patients into proximity with medical researchers. Nor were those beds and laboratories to be dedicated to any special problem. "The only criterion," a newspaper columnist wrote in a retrospect, was "that its special facilities are needed to accomplish certain studies on [patients] which competent investigators, with the patient's cooperation wish to undertake." " Freedom of inquiry for the researchers and patients alike was the explicit mandate, and Means had envisioned Ward 4 as a collaborative environment where physicians and patients worked together to understand the finest details of their conditions. ${ }^{9}$ As Means later explained, "here Nature sets the problem to be solved," and solve those problems at nature's pace the doctors and their patients did. ${ }^{10}$

Patients would often be in Ward 4 for months, sometimes on restricted diets and in completely controlled circumstances meant to allow the team of nurses, dieticians and researchers to elucidate details of metabolic dysfunction. ${ }^{10}$ It would become part of the ethos of Ward 4 that the patients were the primary knowledge keepers of their conditions and that they should be seen as indispensable, equal collaborators in pursuing the cause of medical research "for their own benefit and 
that of others," as an honorary plaque celebrating the ward declared to all who read it later.

Charles Martell may well have been the first patient to enter Ward 4 as a referral from outside of Boston. Subsequently, reporters would detail the variety of cases that could be found there throughout the 1930s, 40s and 50s, often revisiting Martell's case as well. After Means published his history of Ward 4, a reviewer of that book in April 1958 commented: "of the ten patients in the ward, at least eight presented problems which fit no standard classification" and observed that this was "the usual, rather than the rare type of patient." 11

Martell's subsequent experiences, however, hardly make for happy reading, and they were undoubtedly typical of those who followed him. He was investigated for years. He underwent exploratory surgeries and experimental treatments, while he slowly deteriorated. By 1932, after his ninth surgery, the cause of his illness, a small tumour in his chest cavity, was found. He might have begun the process of healing, but, unfortunately, Martell succumbed to a secondary infection caused by kidney stones shortly thereafter. "He died," Means observed later, "so that others might live."11 Indeed, by 1972, as the Massachusetts General Hospital Newsletter reported, 500 operations for hyperparathyroidism had occurred there, largely in the style of
Martell's successful, albeit fatally late, operation. In this way, Martell achieved his heroic renown. ${ }^{12}$

It is self-evident that circumstances might have played out differently for Martell had he never found his way to Massachusetts General Hospital. If he had never been discovered by Means and his colleagues, Martell might not have been discovered at all, and in this sense he would have remained inexplicable, to himself and to his doctors, with all that would have implied for the unfolding of his life.

Of course, he was discovered. Yet, it seems certain that many potential first patients were not so lucky. They probably never found their doctor in the past, and thus they existed in the liminal space of history and knowledge. Such observations are not meant to imply that inexplicable patients avoided medical attention (presumably they sought and found care) but rather to suggest that to describe a patient as unclassifiable or inexplicable required an act of openness on the parts of doctors, patients and institutions to the possibility of a first.

\section{Stephen Casper PhD BSc}

Department of Humanities and Social Sciences, Clarkson University, Potsdam, NY

Acknowledgements: The author thanks John Burnham, Thomas Schlich, Jaipreet Virdi-Dhesi and three anonymous reviewers for their comments on earlier drafts; and Jeff Mifflin (Massachusetts General Hospital archives) for his gener- osity. All materials used in this article are available from Archives and Special Collections at the Massachusetts General Hospital, Boston, Massachusetts, in folders "Ward 4 (Mallinckrodt)," "Martell, Charles (Patient)" and "Means, James Howard."

\section{References}

1. Bauer W, Federman DD. Hyperparathyroidism epitomized: the case of Captain Charles E. Martell. Metabolism 1962;11:21-9.

2. Schlich T. The origins of organ transplantation surgery and laboratory science, 1880s-1930s Rochester (NY): The University of Rochester Press; 2010:53-64.

3. Spencer SM. That fantastic gland, the thyroid Saturday Evening Post 1948 Apr. 10.

4. Bacopoulos-Viau A, Fauvel A. The patient's turn, Roy Porter and psychiatry's tales, thirty years on. Med Hist 2016;60:1-18.

5. Casper ST, Jacyna LS, editors. The neurological patient in history. Rochester (NY): University of Rochester Press; 2012.

6. Ring A, Dowrick CF, Humphris GM, et al. The somatising effect of clinical consultation: what patients and doctors say and do not say when patients present medically unexplained physical symptoms. Soc Sci Med 2005;61:1505-15.

7. Zmecnik P. Presentation of the Kober Medal from 1966 to Joseph Charles Aub. Trans Assoc Am Physicians 1966;79:84-98.

8. Menzies I. M. G. H.'s Ward 4 writes epic of courage: patients join doctors in battle against disease - treated as humans, not as guinea pigs. Boston Globe 1958 Apr. 28

9. Means JH. Ward 4: the Mallinckrodt Research Ward of the Massachusetts General Hospital. Cambridge (MA): Harvard University Press; 1958.

10. Burns F. They eat the same thing every day 3 times. Boston Globe 1949 May 22.

11. MGH research ward's story told. Traveler 1958 Apr. 23.

12. Captain Charles Martell sailed uncharted seas: saga of a Captain Courageous. MGH News November 1972;31:3-6.

This article has been peer reviewed.

CMAJ 2016. DOI:10.1503/cmaj.160111

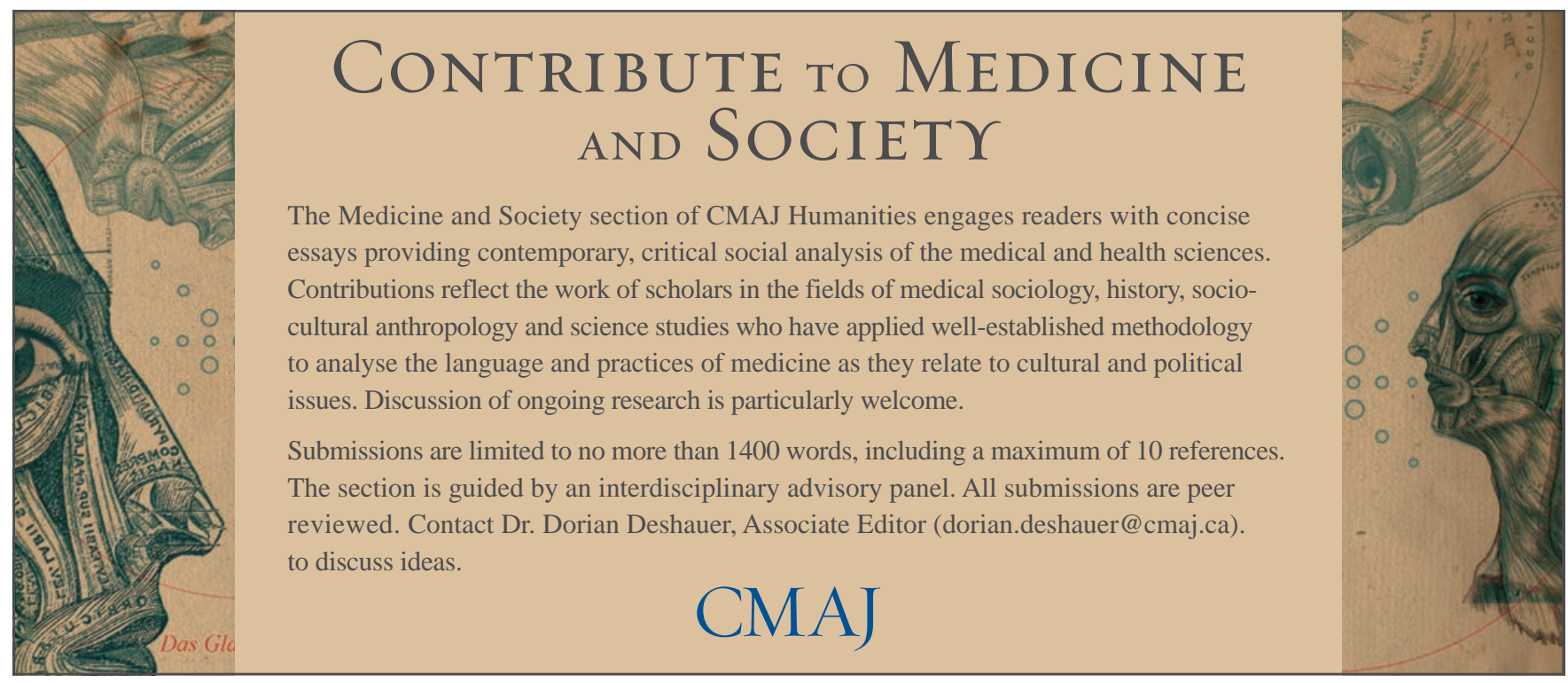

